\title{
Investigating the Shared Background Required for Argument: A Critique of Fogelin's Thesis on Deep Disagreement
}

\author{
DANA PHILLIPS
}

Department of Philosophy

McMaster University

Hamilton, $O N$

Canada

danamaba@yahoo.com

\begin{abstract}
Robert Fogelin claims that interlocutors must share a framework of background beliefs and commitments in order to fruitfully pursue argument. I refute Fogelin's claim by investigating more thoroughly the shared background required for productive argument. I find that this background consists not in any common beliefs regarding the topic at hand, but rather in certain shared procedural commitments and competencies. I suggest that Fogelin and his supporters mistakenly view shared beliefs as part of the required background for productive argument because these procedural commitments become more difficult to uphold when people's beliefs diverge widely regarding the topic at hand.
\end{abstract}

Resumé: Rober Fogelin avance que des interlocuteurs doivent partager un arrièreplan de croyances et d'engagements de fond afin de poursuivre fructueusement des arguments. Je réfute cette position en examinant à fond ce qui est nécessaire pour une argumentation productive. $\mathrm{Ce}$ terrain en commun ne consiste pas en des croyances partagées sur un sujet en cours, mais plutôt d'un partage de certaines compétences et de certains engagements de procédures. Je propose que Fogelin et ses partisans adoptent par erreur l'idée que les croyances partagées font partie de l'arrière-plan d'un échange argumentatif productif parce que ces engagements de procédure deviennent plus difficiles à maintenir lorsque les croyances des gens divergent beaucoup sur un point en litige.

Keywords: Deep disagreement, Fogelin, framework propositions, background beliefs, common ground, cultural distance, intercultural argumentation

\section{Introduction}

In 1985, Robert J. Fogelin published a short article entitled "The Logic of Deep Disagreements," which was republished, along with a collection of critiques and commentaries by other authors, in 2005. In this article Fogelin claims that interlocutors must share a certain framework of background beliefs (what he calls 'framework propositions') and commitments in order to fruitfully pursue argument. He argues that there are cases, called 'deep disagreements,' where interlocutors hold clashing

(C) Dana Phillips. Informal Logic, Vol. 28, No. 2 (2008), pp. 86-101. 
background beliefs that prevent them from resolving an issue rationally even when they agree about all the facts of the matter, maintain a rational disposition and argue non-fallaciously. Therefore, some disagreements are not rationally resolvable through argument.

Fogelin's assertion may have very negative implications for the power of argument in multicultural societies, where a common framework of background beliefs is often likely to be lacking. In such societies there is frequent interaction and thus frequent argumentation between people with deeply rooted differences in background values and beliefs, established by the intersecting influences of family, ethnicity, gender, ability, sexuality, religion, nationality, occupation, class and other social groups, a set of differences that I refer to as cultural distance. However, the implication of Fogelin's claim depends on what exactly the common background required for productive argument (argument leading to a rational resolution of the issue at hand) consists in, a matter about which he is quite vague. It is the precise nature and extent of this background that I investigate in this paper.

Through this investigation, I attempt to reaffirm the capacity for culturally distanced individuals to rationally resolve their disagreements through argument by debunking Fogelin's central claim. After clarifying the meaning of this claim, I proceed to refute the arguments of Fogelin and his supporters in order to demonstrate that the potential for fruitful argument does not require any common beliefs, values or preferences with respect to the topic at hand (though it does require a degree of shared semantic beliefs).

I then go on to suggest that the common ground required for productive argument amounts to certain joint procedural commitments and competencies with respect to the argumentative exchange itself, which I itemize and explain with the use of examples. Finally, I propose that the apparent difficulty of arguing effectively without a common framework of background beliefs can be explained by the increased difficulty of upholding the abovementioned procedural commitments and competencies when few beliefs are shared.

\section{Clarifying Fogelin's Meaning}

Fogelin suggests that in cases of deep disagreement, where arguers do not share a common framework of background beliefs and commitments with respect to a given topic, the conditions necessary for argument no longer obtain. His claim, however, should not be interpreted too literally. Fogelin does not mean that interlocutors involved in a deep disagreement cannot continue to give reasons for their conclusions, but rather that their attempts to argue are futile because their disagreement is not rationally resolvable. As he says, "The language of argument may persist, but it becomes pointless..." (Fogelin, 2005, p. 7). Throughout my paper I will employ Fogelin's understanding of what it means for the conditions of 
argument to obtain, or (in other words) for argument to be possible. My discussion of the possibility of arguing in different situations, then, refers more precisely to the possibility of arguing effectively towards a rational resolution of the issue. To clarify my meaning, I will refer to arguments that progress towards a rational resolution as 'productive.'

I say "progress towards a rational resolution" because real-life instances of argument often do not end with a clear resolution of the issue at hand. And, while this indicates that the successful progression of argument was halted at some point along the way, it does not necessarily mean that the argument leading up to that point was futile, or that the issue is not rationally resolvable. In the moment of an argument, interlocutors will often refuse to or simply fail to respond rationally to new evidence, opposing arguments, or challenges to their own beliefs. If the issue remains unresolved after the initial argumentative exchange has run its course, it may seem that the reasoning process has failed, and thus that the argument was ineffective. However, such an exchange often begins a process of reflection in the minds of the arguers that leads to an eventual rational resolution of the disagreement. It may also be followed by a series of related future exchanges.

It is important to recognize that belief revision does not always work like an on-off light switch. Instead it can involve a tentative unsettling of a belief that will eventually lead to its dislodgement. A good analogy is that of pulling a tooth: once the tooth is loose, you have to go around wiggling it for a few weeks before it will come out. If this is the case, then we cannot measure the success of an argument merely by whether the issue is rationally resolved on the spot. Argument can also prove effective by beginning a process of reflection leading to eventual resolution, even if the argument's advancement is thwarted in the shortterm.

\section{Refuting Fogelin and his Supporters}

Fogelin is right that productive argumentative exchanges do presuppose some shared beliefs between interlocutors. First and foremost, it is crucial to recognize that argumentation implies communication, and communication requires shared beliefs about meanings. Productive arguers need not agree upon the meaning of every word in a given language; in fact, there is no fixed set of beliefs about meanings that they must share. However, they must agree on the meanings of at least some terms or signs in order to understand each other at all. Without these basic shared semantic beliefs, there is simply no means by which arguers can express knowledge, preferences, beliefs and reasons to each other.

At first glance, this seems to support Fogelin's point that productive argument requires a shared framework of background beliefs. However, it is clear from his examples of deep disagreements that this is not all he means. For instance, Fogelin identifies the belief that social 
groups can have moral claims against other social groups as a framework proposition in an affirmative action argument. This shows that his notion of a framework proposition includes more than just beliefs about linguistic meanings; it includes beliefs about the world, outside of language. It is, moreover, the inclusion of these types of beliefs as ones that must be shared between arguers hoping to rationally resolve a disagreement that makes his thesis controversial. Consequently, my discussion of background beliefs throughout this paper will generally focus on, and should be interpreted as referring to, these non-semantic beliefs.

In many of his examples, Fogelin seems to exaggerate the shared non-semantic background required to make productive argument possible. This is partly due to his failure to recognize that personal preferences, uncontroversial facts, and even background beliefs, can be made explicit and subjected to rational discussion within an argumentative exchange. According to Fogelin (2005), no argumentative progress can be made in deep disagreements because "the sources of the disagreement - the framework propositions - are allowed to lie in the background" (p. 8). Fogelin recognizes that this suggests the simple solution of making the framework propositions explicit and arguing about them directly. However, he goes on to explain that this is not actually possible because the framework propositions turn out to be "a whole system of mutually supporting propositions (and paradigms, models, styles of acting and thinking) that constitute... a form of life" (Fogelin, 2005, p. 9). Not only is this quite unclear, it also fails to answer the question of why framework propositions are off limits for rational discussion. Propositions may be interrelated in a complex web of support, but they are still uniquely identifiable objects of belief that can be independently discussed (or discussed with reference to their supporting propositions, which may in turn be discussed, and so forth). Granted that untangling and working through such a web of propositions may be an onerous and unsettling task, which arguers may be reluctant to undertake when beliefs central to their worldviews are at stake. Still, that doesn't make it impossible.

Perhaps Fogelin's point has more to do with the difficulty of recognizing and articulating background beliefs in the first place. This is a very well-founded concern. While most people can articulate some of their implicit assumptions should the need arise in the course of argument, that ability is always restricted to some degree by imperfect language skills and limited consciousness of thought. Articulating framework propositions, furthermore, can be especially challenging because they tend to be taken as given by the person, and the person's society (or at least the communities within that society to which she belongs) in most day-to-day contexts.

I do not deny that the need to articulate framework propositions and subject them to rational scrutiny poses a real threat to the successful advancement of argument in many cases. I do, however, think that 
Fogelin misclassifies the nature of the problem. He suggests that the above requirement renders productive argument theoretically impossible in some situations. This implies that there is no way to overcome the obstacles inherent in articulating and reasoning about framework propositions - in some cases, we will simply never be able to identify and discuss the beliefs that need to be discussed in order to continue arguing productively.

It seems, however, that people can improve their ability to articulate and rationally discuss framework propositions. In fact, engaging in argument with others, especially those who hold drastically different sets of beliefs, is one of the best ways to develop this skill. Background beliefs that go unchallenged are hard to articulate; but the more we are forced to defend our views against others who think differently, the more likely we will be to discover and question the deepseated assumptions that lie behind our own thinking. Certainly, there may be struggles along the way, and we may not always succeed. Still, the struggle to pinpoint framework propositions and subject them to rational scrutiny seems much more fairly portrayed as a practical, or what I will later specify as a 'procedural,' challenge to productive argument than as a theoretical barrier to it.

To continue my analysis of what, other than semantic beliefs, must be shared between productive arguers, I consider the arguments put forward by three authors who support Fogelin's view: Dale Turner and Larry Wright (writing together) and Christian Campolo. According to Fogelin and his supporters, the very possibility of arguing productively requires interlocutors to share a set of background beliefs and commitments pertaining to the issue at hand. This view, however, seems to be a mere consequence of their unsuitably restricted conception of productive argument. In order to examine why reasoning fails to resolve disagreements in certain situations, Fogelin et al. attempt to compare these situations with ones where reasoning is unquestionably successful. Their examples, however, are limited to cases where interlocutors attempt to reason towards a mutually acceptable conclusion, mainly by citing and rearranging evidence from a pool of already shared beliefs. Fogelin's primary example involves two people appealing to local geography and traffic conditions to decide which groceries to buy next, while Campolo presents the scenario of two surgeons deciding how to alter a surgical procedure in light of new medical evidence.

Turner and Wright offer similar exemplars of productive argument. They depict a series of cases in which one party argues briefly for a conclusion that is easily accepted by the other party on the basis of the evidence cited. While admitting that such an exchange might be complicated by some initial disagreement, they insist that people who share most of the beliefs relevant to the topic at hand will know how to settle the matter through further reasoning. Turner and Wright's (2005) belief that these scenarios represent a paradigm of productive argument is clear when they later refer to "those quotidian uses of argument form that 
establish our expectations of it," and when they compare philosophical arguments to "a 'normal' episode in which a reason simply ends a debate by appeal to a shared competence" (p. 31).

Fogelin et al. emphasize that the interlocutors in their examples argue successfully towards a rational resolution of the issue at hand by appealing to shared knowledge, beliefs and preferences. This point is well taken. However, the fact that people who happen to share a large common background of knowledge, beliefs and preferences tend to argue by appealing directly to that background does not prove that people with less in common cannot argue productively.

Moreover, one must question why the type of episode depicted by these authors, where there is little to no disagreement between parties to begin with, has been picked as the normal standard to which other potential instances of argument ought to be compared. This is especially troubling considering that Fogelin's thesis on deep disagreement seems most concerned with arguments where interlocutors genuinely disagree about some important issue. According to Fogelin's portrayal, cases of deep disagreement occur when arguers have a significant disagreement but are unable to resolve it rationally due to a lack of common background beliefs. His examples include debates over abortion and affirmative action, not which groceries to buy next. Shouldn't the successful cases of argument used for comparison, then, be ones where the parties involved face a serious disagreement which they are able to resolve by appealing to a shared framework of background beliefs? (Perhaps Fogelin means to suggest that no such case exists. That, however, implies that argument can be successful only in resolving minute disagreements, which seems overly pessimistic and highly implausible.)

Fogelin et al.'s strategy of comparing successful instances of argument to unsuccessful ones in order to determine the general conditions necessary for productive argument seems fair enough. The mistake they make, however, is to assume that the simplest examples will best illustrate what makes an argument successful. This appears, in fact, not to be the case.

In addition to shared background beliefs and commitments, both Turner and Wright and Campolo indicate the need for productive arguers to have 'shared competence' with respect to the topic at hand. What that competence amounts to depends on the situation. For instance, in one of Turner and Wright's examples, students arrive at their professor's office hour only to find the professor missing. In reasoning from the evidence of the open office door and steaming coffee cup on the desk to a conclusion about the professor's whereabouts, the students' implicit assumptions include the knowledge that coffee is a beverage often consumed at work, that it cools fairly quickly at room temperature, that coffee does not spontaneously materialize, that professors close their doors before leaving for the day, etc. None of these assumptions, however, are grounded in any particular field of expertise. The students' 
shared competence in this scenario comes from a basic understanding of the laws of nature and the work practices of professors, generally acquired without much effort by anybody exposed to a university or other office environment.

Contrast this to Turner and Wright's example of an argument in paleobiology concluding that every organism alive today has a certain type of common ancestor that lived three billion years ago. Suppose Dr. Paleo supports this conclusion with evidence of how ribonucleic acids work, their mutation rates, geophysical history, etc. In making this argument, she is assuming a great deal of knowledge shared mainly by paleobiology experts. Were she to present the argument to a layperson (call him Layperson), he would lack that common background and would therefore be unable to follow her reasoning. Turner and Wright suggest that in such a case, it is (or ought to be) recognized that Layperson needs to develop a certain competence in paleobiology before he can possibly engage in argument with Dr. Paleo on the matter at hand.

Consider one more example. Suppose two citizens at a public execution are debating whether or not capital punishment is morally permissible. What shared competence do they need in order to reason productively towards an answer to this question? Surely some sort of expertise in ethical matters is called for. Yet who could possibly declare themselves to be a truly competent judge of ethics? With respect to these sorts of arguments, Turner and Wright (2005) suggest: "their interminability among uncontroversially informed and intelligent people makes it fairly clear that they lie at the outer edge of our competence and understanding" (p. 31). Campolo (2005) adds, "our joint reasoning in such cases cannot be better than our joint competence-and that is quite low" (p. 44). In other words, humanity's general lack of competence regarding these matters means that they cannot really be resolved through argument.

The argumentative exchange where shared competence results from basic common knowledge within a given society (traffic and office hour examples) and the exchange where expert competence is shared (surgery and paleobiology examples) are the two standard models of productive argument presented by Fogelin and his supporters. According to them, when the subject matter is such that no person can claim competence, such as with philosophical issues, or when one party lacks a certain competence that the other possesses, reasoning loses traction.

Although Turner and Wright and Campolo indicate some important practical challenges to productive argument, they fail to prove that shared competence is a necessary initial condition for successful reasoning in any of their examples.

Take Turner andWright's paleobiology argument, for instance. Layperson may be unable to follow Dr. Paleo's reasoning initially, but Dr. Paleo can help him to overcome this throughout the course of argument by making him aware of certain accepted facts in the field of paleobiology. There is nothing extra-ordinary about this; productive 
arguers often fill in gaps in each other's knowledge simply by informing each other of certain uncontroversial particulars. Granted, it may take time to really grasp the meaning of some information, and it is always possible for a person to doubt the things cited by her interlocutor. Still, arguers can top up each other's information to create a shared base of accepted facts from which both parties can then reason. And that can be part of the argumentative process. If, during A and B's argument about which groceries to pick up next (Fogelin's example), A does not know or is mistaken about the location of a particular grocery store, could not B simply inform her of this fact?

In response to this, Fogelin et al. would likely suggest that disclosing a few facts to one's interlocutor while arguing differs in kind from inculcating competence in a highly specialized field such as paleobiology. Certainly, if Dr. Paleo wanted Layperson to understand her reasoning exactly, she would have to explicitly present a lot of background knowledge not directly related to the argument at hand. In that case, her actions might be better classified as giving an education than as making an argument.

However, Dr. Paleo would likely be able to simplify her argument considerably, and thereby the information she needs to impart, without sacrificing clarity regarding her main line of reasoning. Scientists often do this for lay audiences in order to present their cases to the public. In this scenario, only a limited number of facts directly concerned with the argument at hand need to be related by Dr. Paleo to Layperson; her expertise itself need not be transferred. And, as previously discussed, those facts can be communicated throughout the argumentative process; they need not be shared initially. So, while it is true that Dr. Paleo must instill a certain degree of competence in Layperson for productive argument to proceed, no initial shared competence is required.

What about the capital punishment debate? Firstly, the fact that ethical debates are interminable does not necessarily imply that humans lack the competence to deal with them. Competence does not always mean being able to find the right answer, something philosophers, social scientists, politicians, artists and many others will attest to. It has more to do with possessing in-depth knowledge of an issue, its social and historical context, and the arguments that have been put forth by proponents of different beliefs with respect to it, which allows one to form educated judgments and beliefs. It is not humanity's overall lack of competence regarding ethical matters (though some people certainly possess more competence than others) that leads to their interminability but rather the non-verifiable and non-falsifiable nature of answers to ethical questions.

There are of course many people who do lack competence regarding ethics, or at least with respect to a particular ethical matter. Neither the interminability of ethical debates, however, nor interlocutors' potential lack of competence regarding them, eliminates the possibility of arguing productively about such matters, not to mention the importance 
of doing so. In fact, the severe limit that Fogelin et al.'s view places on the productive application of argument to these kinds of issues engenders suspicion in itself. Reasoning, after all, allows interlocutors to make the most of the evidence they possess in evaluating a particular issue, even if that evidence is slight. It is not the job of productive argument to lead us to a single objectively right answer, or even to an objectively good answer. Rather, productive argument should bring us closer to the rational resolution of a particular disagreement by forcing us to re-assess our own beliefs alongside the beliefs of our interlocutor, given the evidence jointly available.

Turner and Wright give three reasons why argument regarding controversial topics such as the morality of capital punishment cannot gain any foothold. Firstly, the sources of disagreement between interlocutors on such matters often lie in implicit assumptions that can be difficult to recognize. Secondly, the basis of disagreement, once discovered, may not be something that interlocutors normally think they can settle through reasoning. Thirdly, the practical urgency of resolving the issue often prevents a proper analysis from taking place (Turner and Wright, 2005, p.32). What is important to note is that all these problems are practical, and not theoretical. They may very likely obstruct the flow of rational discussion, but they are by no means insurmountable barriers to argument.

At this point I should note that Turner and Wright and Campolo's conceptions of deep disagreement vary somewhat from Fogelin's. Turner and Wright (2005) portray the distinction between normal (productive) arguments and deep disagreements as one between giving reasons against "a stable background of understanding and competence" versus altering the background itself (p. 31) ${ }^{1}$. For them, reasoning about background beliefs is merely the activity that makes productive argument possible. One problem with this approach is that it fails to indicate what counts as a background belief. Another is that it limits the scope of productive argument unnecessarily and unhelpfully.

Unlike the archetypal examples given by Fogelin and his supporters, many productive argumentative exchanges do not end with one party's immediate acceptance of the first argument presented by the other party. In a heated debate, for example, interlocutors are not attempting to reason towards a mutually acceptable conclusion to some question, but rather to rationally persuade each other of their own points of view. In such cases, one party often directly challenges the other's initial argument, either by questioning the truth of one or more of its premises, or by questioning whether the premises provide sufficient support for the conclusion. At this point, background beliefs become the

\footnotetext{
${ }^{1}$ Turner and Wright attribute this view to Fogelin. However, a closer reading of Fogelin suggests that he does allow for the possibility of addressing background (framework) propositions in the course of argument. Of course, he then goes on to suggest that these propositions cannot actually be articulated and rationally assessed (Fogelin 8-9).
} 
subject of rational scrutiny (even if main premises don't count as background beliefs, the premises that support them likely do). Yet it hardly seems plausible to say that these interlocutors are no longer engaged in productive argument as before. They are, after all, still appealing to reasons to justify statements that ultimately bear upon the initial conclusion advanced. What else can they be said to be doing? Granted, an argumentative exchange might become thornier when dealing with background beliefs, and the path to resolution less clear. But argument, even when it works, is not the lucid process that some philosophers might like it to be.

Campolo's point differs somewhat from the others. Unlike Fogelin and Turner and Wright, he does not claim that the conditions for productive argument cease to exist when there is a lack of shared understanding or competence, but rather that reasoning becomes practically ineffective and even potentially harmful. Campolo gives the example of a team of contractors faced with the entry of a pack of wild dogs onto their building site. While the team may possess joint competence in matters of contracting, they do not possess the same expertise with respect to dealing with wild dogs. Thus, says Campolo, the team ought to limit their reasoning to the subsidiary matter of who to call about the problem. Were they to reason together about how to deal with the dogs themselves and happen upon a good solution, they would be encouraged to use reason in other similar situations where the result might not be so lucky. What Campolo fails to recognize, however, is that calling an expert is not separate from other options for dealing with the dogs. The team does not choose to either reason towards a solution or call an expert, they simply reason about what to do next. And this process itself should lead them to realize that calling an expert is the best thing to do. So, in this situation, reasoning still plays a crucial role.

Beyond the proposed requirement of shared competence, Turner and Wright remark that cases of practical reasoning (reasoning about what should be done) also call for shared values and preferences. According to them "even greatly expanded life experiences will frequently make little headway against different pictures of the good" (Turner and Wright, 2005, p. 30). This implies that values, or practical ends, are beyond the reach of reason. Donald Hatcher promotes a similar viewpoint. However, as he admits in response to criticism, values are actually based upon intricate networks of beliefs that can be rationally assessed, at least in theory. He puts it as follows: "People might at first disagree on the weight given to an argument depending on their world view, but the next step is to evaluate the reasonableness of the world view" (Hatcher, 2003, p. 6).

In chapter XIII of Practical Reasoning About Final Ends, Henry Richardson develops this idea in detail. He presents a holistic model for the rational deliberation (practical reasoning) process of a single individual, where a person's analysis of the decisions he has made in cases analogous to the one presently before him allows him to reflect upon and thereby to revise and further specify his initial ends. In chapter 
XI, Richardson extends this model to interpersonal disagreements that involve what he terms 'incommensurable conceptions of the good'. To resolve this incommensurability, he advocates a holistic dialectic where arguers make use of four dialectical tools: specification, abstraction, distinction and analogy. Because it is not bound to work within a single theory, he argues that the holistic process of reflection facilitated by this sort of dialectic has the potential to bring opposed theories, or conceptions of the good, into line.

As Richardson notes, it is not so much that the absolute values of individuals differ but rather that they are specified and prioritized in different ways. For instance, one of the contractors in the above example might say: 'Our safety is most important. We ought to call my husband the hunter to shoot the dogs on the spot'. The priority she gives to safety in this circumstance is perhaps based on the belief that human life is more important than animal life. Alternatively, she may assert the value of animal life, but specify that value as applying only to domestic animals, or to wild animals in their natural habitat. Suppose that another team member responds: 'Animal life is valuable. We should wait for animal control even though it will take longer'. Her stance may be supported by the belief that human life and animal life are fundamentally similar, and thus of equal worth. She may also believe that her life is not seriously endangered in the situation, so killing the dogs would be an unnecessary act of cruelty. All of these beliefs can be supported or refuted by evidence, which itself can be supported, refuted, or further elucidated, as necessary.

Fogelin raises one more alleged requirement for productive argument that has yet to be dealt with. He insists that productive arguers must at least agree on the appropriate procedure for resolving their disagreement (Fogelin, 2005, p. 6). The example he gives is of two people, call them Boris and Doris, agreeing to resolve their disagreement about a baseball statistic by looking it up in a record book. According to Fogelin (2005), "If the record book does not convince you, then it's a waste of time talking to you" (p. 6). That, however, seems unfair. There must be room in the argumentative exchange for Boris to propose that the record book is in fact unreliable, since (let us suppose) he has found many other errors in books by the same publisher. The record book provides strong evidence, but it is still only evidence, and can therefore be contested. As Richard Feldman points out, another equally credible source may give a different statistic, which ought to lead Boris and Doris to suspend judgment about the matter, at least until they research further (Feldman, 2005, p. 16). It is also possible that Boris attended every baseball game of the season, and believes that his eyewitness testimony provides stronger evidence for the statistic than a record book. The disagreement here is not really about the method of resolution, but about the strength of the evidence. And, as suggested above, argument can quite plausibly proceed to address that question.

It seems, then, that productive argument can and often should proceed even in situations where interlocutors do not share common 
background beliefs, competence or values regarding the subject matter at issue. More importantly, it is hard to imagine any situation where the lack thereof could preclude the very possibility of arguing productively. In the opening lines of The Web of Belief, Quine declares that science is not a private club. He says "scientific inquiry can be undertaken by anyone on almost any subject matter" (Quine, 1978, p. 3). It is but a short step to extend this to reasoning in general.

\section{Procedural Commitments and Competencies Required for Argument}

The possibility of rationally resolving a disagreement does not, in theory, require any antecedent common beliefs about the topic at hand. It does, however, require certain joint procedural commitments and competencies with respect to the argumentative exchange itself. For instance, consider the above example involving the baseball statistic. Even if Boris suggests that the record book is unreliable, Doris might stubbornly refuse to consider that possibility (that is easy enough to imagine). And, so long as she is unwilling to engage in reasoning about whether the book is reliable or not, the rational resolution process cannot advance any further, at least not in that particular direction. Thus, the willingness of arguers to subject challenged beliefs to rational appraisal is a crucial requirement for the successful progression of argument.

In their article "Rationale for a Pragma-Dialectical Perspective," Frans Van Eemeren and Rob Grootendorst (1988) put the point as follows: "Whoever advances a standpoint is obliged to defend it if asked to do so" (p. 11). In fact, they list this as one of the ten rules of conduct that they believe interlocutors must follow in order to rationally resolve a dispute through argumentative discussion. Following the work of Barth and Krabbe, they refer to these rules of rational discussion as first order conditions. These are distinguished from higher order conditions which set out the attitudes of the discussants (second order) and external circumstances of the discussion (third order) that are necessary to make adherence to the first order discussion rules possible.

My aim to elucidate the procedural commitments required for productive argument is similar to Van Eemeren and Grootendorst's goal in setting out first order rules for critical discussion. I have drawn from their work for that reason, although my list does not quite match up with theirs, since it excludes some of the conditions that strike me as redundant or not strictly necessary. Because their second order rules regarding the attitudes of interlocutors are, in a sense, prerequisites for the first order ones, they are also implicitly included in my list of procedural commitments. Third order conditions, on the other hand, discuss factors that are beyond the control of interlocutors. While these are obviously an important aspect of argumentative exchanges, I am not concerned with them in this paper, since my focus is on what arguers 
need to have in common in order to argue and not what the external circumstances of their discussion must be.

Let's return for a moment to the example of Boris and Doris discussing the baseball statistic. Suppose Boris gives Doris many good reasons to think that the record book is unreliable, so that it is rational for Doris to change her mind and believe Boris' conclusion. That is no guarantee that Doris will in fact change her mind, since she may not behave rationally. Alternatively, Boris may give reasons that ought not to persuade Doris, but Doris may change her mind anyway, without good reason. Argument, however, rests its effectiveness on its appeal to human epistemic rationality. When one party to an argumentative exchange gives up the commitment to respond rationally to evidence, the whole point of argument is lost and the exchange becomes futile (though as previously discussed, the commitment to rationality, and thus the effectiveness of the argument, may still be upheld in the long-term). This once again demonstrates the need for productive arguers to share a joint procedural commitment to maintain a rational stance.

Another procedural commitment required for productive argument that is listed by Van Eemeren and Grootendorst (1988) as a first order discussion rule is that "Parties must not prevent each other from advancing or casting doubt on standpoints" (p. 11). Only with this basic freedom of expression can the knowledge, beliefs, and reasons of both participants be considered comprehensively, as productive argument requires. This first order condition, moreover, corresponds to the requirement that "the persons concerned must...possess a second order discussion attitude which involves the willingness to express their opinions and to listen to the opinions of others" (Van Eemeren and Grootendorst, 1988, p. 17). Because the first order condition here presupposes the second order condition, the latter need not be listed as a separate procedural commitment. Nevertheless, it provides a useful guideline for what the initial commitment entails.

Van Eemeren and Grootendorst's (1988) final first order rule states: "Formulations must be neither puzzlingly vague nor confusingly ambiguous, and must be interpreted as accurately as possible" (p. 12). This points to yet another shared commitment that must obtain between interlocutors for them to argue productively: their joint commitment to communicate sincerely and transparently. Suppose, for instance, that Boris deliberately deceives Doris by lying about what the baseball record book says. Boris' lack of honesty corrupts the rational quest for truth about the matter of baseball statistics in which Boris and Doris were formerly engaged. It signifies his decision to abandon reason in favour of another method of persuasion (deception).

Insincerity in argument can also work in more subtle ways. In his theory of argumentation, Mark Vorobej introduces a property of 
argument called 'normality', By his definition, an argument is normal just in case the author of the argument "consistently believes that she herself, as well as those whom others perceive to be the targets of her argument, ought to be persuaded by her own argument" (Vorobej, 2006, p. 111). So, if Xena is presenting an abnormal argument to Xavier, either she does not truly believe that Xavier ought to be rationally persuaded by her argument, or she does not rationally endorse the argument herself (or both). Abnormality does not necessarily imply insincerity or a lack of transparency, so long as Xena makes her belief about the argument's rational force for Xavier and for herself clear. For instance, it is quite plausible for Xena to reason from Xavier's commitments to some conclusion she wishes Xavier to accept, all the while making perfectly clear that she does not share Xavier's initial commitments. However, it is also easy to imagine a situation where Xena purposely neglects to make her position with respect to the argument explicit. Imagine, for instance, that she is a mother reasoning to her young son: 'You should eat your vegetables because that's what keeps your hair from falling out!' It is likely that she does not believe the child ought to be rationally persuaded by her argument, or at least that she herself does not find the argument rationally persuasive. Yet, she hopes it will do the trick in making him eat his vegetables. In this case, Xena is clearly hiding something about how she perceives the argument from her son, and as a result the integrity of the rational exchange disintegrates.

Other necessary conditions for productive argument depend not on the approach taken by arguers, but on their abilities. As previously discussed, arguers must be able to pinpoint the basis of their disagreement. Otherwise, they may give reasons until they are blue in the face without ever addressing the real difference in belief that leads them to endorse separate conclusions. Suppose, for instance, that James and Aretha are arguing about the existence of God. For James, 'God' means the creator of the universe, but for Aretha 'God' means the spirit that unifies the universe. Suppose, furthermore, that James and Aretha both believe there is a spirit that unifies the universe, but neither believes that the universe has a creator. James says that God does not exist, and Aretha counters that God does exist. Because they each take 'God' to mean something different, they will continue to give reasons in support of their respective positions without the slightest hope of resolving their apparent disagreement.

While the source of disagreement in the above example amounts to a difference in semantics, it is important to note that this is not what blocks productive argument. Just as interlocutors can smooth the course of argument by making their knowledge and preferences explicit, so can they articulate their differing interpretations of key terms. Were James and Aretha to recognize the disparity in their respective notions of 'God'

\footnotetext{
${ }^{2}$ This should not be confused with Fogelin's notion of normal argumentative exchanges, which is entirely different.
} 
and to discuss the meaning of the term explicitly, they could easily overcome their semantic disagreement and continue to engage in productive argument. However, discussing and clarifying key terms, knowledge, preferences, beliefs, and implicit assumptions does necessitate that interlocutors speak the same language, with a shared understanding of at least the most basic vocabulary, as I have previously mentioned.

\section{The Practical Difficulty of Arguing Without Shared Background Beliefs}

When one considers the shared procedural commitments and competencies required to make productive argument possible, the apparent difficulties of arguing productively without a common background of beliefs are easily explicable. Imagine a spectrum of argumentative contexts. On one side of the spectrum are contexts where interlocutors share most of their beliefs about the given topic, and are thus able to argue quickly and effectively by merely appealing to this common background. Sources of disagreement tend to be fairly superficial and thus easily recognizable. On the other side of the spectrum are contexts where interlocutors' beliefs about the topic diverge at a very deep level. Just to identify the source(s) of disagreement, they must probe through several layers of implicit assumptions. Productive argument is possible anywhere along the spectrum. However, the procedural commitments required for productive argument are much easier to uphold on the side where interlocutors have many beliefs in common, than on the side where they share very few beliefs. On the latter side, those commitments pose a very real threat to the progression of argument.

People with few shared beliefs about the topic they are discussing will probably disagree at a much deeper level, and hence the source(s) of their disagreement will take more work to identify. If they are culturally distanced, they are also likely to share a smaller common base of vocabulary (i.e. semantic beliefs) with which to accomplish this task. And their differences, when they do recognize them, are more likely to concern beliefs that are central to their respective worldviews. Naturally, interlocutors might not be inclined to subject these sorts of beliefs to rational scrutiny. Moreover, addressing these conflicting background beliefs may be perceived as diverting rational discussion too far from the original argument. With respect to social policy, for instance, Turner and Wright (2005) warn: "the felt urgency of these issues naturally undermines the patience required to treat a subject of this depth and subtlety" (p. 32).

People working from drastically different frameworks of belief are likely to lack the time or patience to continue reasoning about underlying controversies. Suppose, for example, that two doctors with 
very divergent beliefs about bioethics must make a quick medical decision that involves serious ethical considerations. A thorough rational analysis of all the conflicting beliefs that cause them to disagree over what to do next could take hours, but the doctors only have minutes. Continuing to argue in this circumstance is impractical. While the doctors may begin by appealing to reasons, they will likely resort to other nonrational methods of persuasion to decide the question quickly.

\section{Conclusion}

What makes productive argument seem impossible in many of the examples given by Fogelin and his supporters, then, is merely a problem of execution. Interlocutors are frequently unwilling or unable to rationally assess certain beliefs, to communicate sincerely, or to recognize where their differences lay. While in theory productive arguers need not have any beliefs about the topic of argument in common, procedural barriers to argument tend to surface in contexts where such shared beliefs are sparse. Being conscious of those barriers and working to overcome them where possible is perhaps the most crucial step to enhancing the power of argument in our world.

\section{References}

Campolo, C. (2005). Treacherous ascents: On seeking common ground for conflict resolution. Informal Logic, 25(1), 37-50.

Feldman, R. (2005). Deep disagreement, rational resolutions, and critical thinking. Informal Logic, 25(1), 13-23.

Fogelin, R. J. (2005). The logic of deep disagreement. Informal Logic, 25(1), 3-11.

Hatcher, D. (2003). The role of personal values in argument evaluation. Informal Logic at 25: Proceedings of the Windsor Conference. 1417 May 2003. [CD-ROM].

Quine, W.V., and Ullian, J.S. (1978). The web of belief. Toronto: Random House.

Richardson, H. S. (1997). Practical reasoning about final ends. New York: Cambridge University Press.

Turner, D., and Wright, L. (2005). Revisiting deep disagreement. Informal Logic, 25(1), 25-35.

Van Eemeren, F., and Grootendorst, R. (1988). Rationale for a pragmadialectical perspective. Argumentation, 2(2), 271-291.

Vorobej, M. (2006). A theory of argument. New York: Cambridge University Press. 